\title{
Parental smoking status affects substance use by adolescents: A national cross-sectional study conducted in Korea
}

\section{Jinhee Lee}

Yonsei University Wonju College of Medicine

\section{Yunna Kwan}

Yonsei University Wonju College of Medicine

\section{Seongho Min}

Yonsei University Wonju College of Medicine

\section{Min-Hyuk Kim}

Yonsei University Wonju College of Medicine

\section{Ka Hye Chun}

Hallym University College of Medicine

\section{Sungwon Choi}

Duksung Women's University

Joung-Sook Ahn ( $\nabla_{\text {jsahn@yonsei.ac.kr) }}$

Yonsei University Wonju College of Medicine https://orcid.org/0000-0003-4255-1831

\section{Research article}

Keywords: parental smoking, adolescent substance use

Posted Date: December 3rd, 2020

DOI: https://doi.org/10.21203/rs.2.20852/v2

License: (c) (1) This work is licensed under a Creative Commons Attribution 4.0 International License. Read Full License 


\section{Abstract}

Background: In the present study, we investigated the association between substance use by adolescents and parental smoking status based on data from the 2016 Korean Youth Risk Behavior Web-based Survey, a national school-based survey.

Methods: Data from a nationally representative sample of Korean adolescents aged 12-18 years $(\mathrm{n}=$ 65,528 ) were analyzed, and the risk of substance use according to the parental smoking status was investigated.

Results: We found that smoking by both parents was a greater risk factor for substance use by adolescents than smoking by any one parent. Moreover, maternal smoking was a greater risk for substance use by adolescents than paternal smoking. We also investigated sex differences in the risk of substance use as a result of the parental smoking status.

Conclusions: Accurate evaluation of the family smoking environment and whole-family interventions are necessary for preventing and intervening in substance use by adolescents.

\section{Background}

Adolescence is a period of vulnerability to various psychological pathologies (i.e. depression, anxious mood) and comprises several physical and emotional changes. Therefore, globally, the health behavior of adolescents is an important public health issue. Unhealthy behaviors such as smoking, alcohol drinking, and drug use usually start in adolescence [1], and the socioeconomic status, parenting quality, peer group influence, and biological/inherent predisposition toward drug addiction constitute risk factors for the initiation of substance use and its increase among adolescents [2]. In addition, alcohol drinking and cigarette smoking during adolescence exerts a major influence on health in adulthood, mental illness, suicidal behavior, and decreased life expectancy [3]. In this context, these substance use by adolescents represents not only an individual health problem but also a social burden, influencing family life, friends, and other members of the society.

Smoking is the most common substance use among young people worldwide. A previous study reported that people who started smoking before the age of 19 years were 2.4 times more likely to become heavy smokers than those who started smoking after the age of 26 years [4]. Considering that $>90 \%$ of adult smokers start smoking during adolescence and that an early smoking onset results in poor health outcomes after adolescence [5], smoking by adolescents is a serious and important issue. Previous study for Korean adolescent had investigated that more exposure to secondhand smoking at home was associated with the higher risks of adolescent's smoking [6].

Another form of substance use is alcohol drinking. The use of alcohol among adolescents has increased recently. It can cause adverse changes in the brain structures that regulate risk and reward systems, thereby increasing the risk of developing alcohol addiction [7]. 
Both early detection of risk factors and intervention are important against substance use; however, adolescents tend to hide or under-report risk behaviors such as substance use [8]. Family influence constitutes a known preventable factor for substance use by adolescents [9]. Adolescents are susceptible to influence of social and environmental factors, and both family history and parental substance use status may motivate substance use in adolescence [9]. A previous study reported that between $5 \%$ and $30 \%$ of the children in high-income countries live with a parent with substance use problems [10]. However, there is no clear consensus on the relationship between substance use by parents and children in prior studies.

In the present study, large-scale nationally representative data were used to identify the risk of substance use by adolescents according to parental smoking status. We hypothesized that the parental smoking status has effects on the probability of substance use by children and that these effects vary depending on the substance use status of each parent, their sex, and type of substance use.

\section{Materials And Methods}

\section{Study population and data source}

Data from the $12^{\text {th }}$ Korea Youth Risk Behavior Web-based Survey (KYRBS) were used[11]. KYRBS, a nationwide cross-sectional study and government-approved statistical survey, was performed by the South Korean Ministry of Education, Science and Technology; Ministry of Health and Welfare; and Korea Centers for Disease Control and Prevention using a stratified multistage cluster strategy. KYRBS is a selfreport, anonymous, online survey performed on a nationally representative sample of Korean adolescents aged 12-18 years. It comprises 129 questions divided into 15 sections about health-related behaviors as well as mental and physical health. In $12^{\text {th }}$ KYRBS, a total of 67,983 students from 800 middle and high schools were randomly selected, and 65,528 (boys $=33,803$ and girls $=31,725)$ students $(96.4 \%$ response rate) from 798 schools ( $99.8 \%$ response rate) responded to the survey. The participants were identified by numbers and were guaranteed anonymity by following method. All participants completed an online, selfreport questionnaire in a school computer room after the survey had been fully explained. Participants were randomly assigned one computer per person, and teachers except the homeroom teacher were assigned as managers. In addition, the managing teachers instructed not to see the computer screen and not to respond to the questionnaire, to ensure the anonymity of responses. The Institutional Review Board of the Korea Centers for Disease Control and Prevention approved KYRBWS (Statistics Korea, approval No. 11758).

\section{Variables}

\section{General characteristics}

The general characteristics of the participants included age, sex, residential area (i.e., metropolitan cities, small and medium towns, and rural areas), family economic status (i.e., high, middle high, average, middle low, and low), paternal and maternal educational levels (i.e., college and higher, high school, 
middle school and below, and unknown), and academic achievement (i.e., high, middle high, average, middle low, and low).

\section{Parental smoking status}

The parental smoking status of the participants was identified using the following question: "Please check all household members who currently smoke." and responses were chosen between the following options: (1) no one, (2) father, (3) mother, (4) siblings, (5) grandparents, (6) others, (7) do not know. We only included data showing more than one response to the following analysis. Considering the impact of parental smoking on adolescents, we recoded responses with a focus on parental smoking and classified into 4 categories: (1) nonsmoking(none of the parents smoke), (2) paternal smoking(the father is a smoker, but the mother is not a smoker), (3) maternal smoking (the mother is a smoker, but the father is not a smoker), and (4) parental smoking(both parents are smokers).

The second-hand smoke exposure at home over the last 7 days regardless of parental smoking status was measured. It was explored by the following question: In the last 7 days, how many days have you been with someone(such as a family member or guest) when they smokes in your home?" and the response were chosen from 0 to 7 days. To statistically adjust for the effects of secondhand smoke in the home, we divided the responses into two categories: "no secondhand smoke experience" and "have secondhand smoke experience"(if the respondent have experienced secondhand smoke for more than one day).

\section{Current substance using status}

Data of Substance use by the participants including alcohol drinking and smoking statuses were used. Their alcohol drinking status included lifetime alcohol drinking, current alcohol drinking, alcohol drinking days, and alcohol drinking volume. Lifetime alcohol drinking was measured with a dichotomous question: "Have you ever drank more than one glass of alcohol?". Alcohol drinking days were measured through following question: "How many days have you drank more than one drink in the last 30 days?" and the responses were coded as days. Alcohol drinking volume was measured by the question, "In the last 30 days, what was the average amount for drinking?" and the response was coded as standard units. Current alcohol drinking item was created by recoding these items: data was recoded as "yes" in the case of reporting more than one day or one unit of drinking in the last 30 days and was recoded as "no" if neither is the case.

Similarly, their smoking status included lifetime smoking experience, current smoking, smoking days, and smoking volume lifetime smoking experience was explored by a dichotomous question: "Have you ever smoked a sip or two?". Smoking days and volume were measured by following questions: "How many days have you smoked at least one cigarette in the last 30 days?" and "On average, how many cigarettes per day did you smoke in the last 30 days?". Amount was coded as cigarettes per day. Current smoking item was created by recoding the data of these two questions. As similar as current alcohol drinking item, data was recoded as "yes" in the case of reporting more than one day or one cigarette smoking in the last 
30 days and was recoded as "no" if neither is the case. Also, Lifetime drug use by the participants was also analyzed. The following dichotomous question was used: "Have you ever habitually or deliberately taken drugs or used inhalant (e.g. butane gas or adhesive)?"

Since the distribution was not revealed as normal distribution, amount and number of days of smoking and drinking variables were divided into several intervals and analyzed with multinomial logistic regression. First, the variables recoded as follow: Regarding alcohol consumption, the responses of days were recoded to 1) not drinking at all in the past month, 2) 1-9 days 3) 10-19 days 4) drinking more than 20 days, and responses of amount were recoded to 1) not at all in the past month, 2) 1-2 standard units(light drinking), 3) 3-4 standard units(moderate drinking), 4) 5 or more units(binge drinking). Regarding smoking, the responses of days were recoded to 1) not smoking at all in the past month, 2) 1-9 days 3) 10-19 days 4) smoking more than 20 days, and responses of amount were recoded to 1) not at all in the past month, 2) less than one cigarette per 1 day, 3) 1-9 cigarettes, 4) 10-19 cigarettes, 5) 20 or more cigarettes per 1 day.

\section{Statistical analysis}

Univariate analysis was conducted to estimate the proportion of smokers among mothers and fathers. One-way analysis of variance and Pearson's chi-square test were performed to estimate the general characteristics (sex, age, education, urbanity, parental education level, family economic status) and second-hand smoke exposure of the 4 groups(i.e., parental nonsmoking, paternal smoking, maternal smoking, and both parental smoking). Binary variables such as lifetime alcohol drinking, current alcohol drinking, lifetime smoking experience, current smoking, and lifetime drug use were analyzed using binary logistic regression. Variables containing more than 3 categories, including the number of days spent drinking alcohol and smoking and the volumes of alcohol drinking and smoking, were analyzed using multinomial logistic regression. The model was statistically adjusted by age, urbanity, academic achievement, parental educational level and socioeconomic status (SES). Finally, to explore whether there was an effect of second-hand smoke exposure, analyses were adjusted for second-hand smoke exposure at home. The statistical analysis was performed not only to all youth but separately to gender because parents' smoking status had different effects depending on the offspring's gender.

\section{Results}

\section{Demographic variables}

Table 1 presents the demographic characteristics of each group according to the parental smoking status. A total of 1,646,394 adolescents living with their parents were included, among which 1,481,156 were in the parental nonsmoking group, 108,934 were in the paternal smoking group, 13,738 were in the maternal smoking group, and 42,566 were in the parental smoking group. Significant differences were found among these groups in terms of sex, age, educational level, urbanity, academic achievement, parental educational level, and SES (all $p<0.001$ ). 


\section{Substance use by adolescents}

Table 2 shows the results of logistic regression regarding the effects of the parental smoking status on substance use by adolescents. Following adjustment for age, urbanity, educational level, parental educational level, SES, and differences in demographic variables, maternal smoking was associated with higher risks of lifetime alcohol drinking and current alcohol drinking among adolescents than paternal smoking, whereas parental smoking had higher risks than maternal/paternal smoking. Also, this pattern is clearly observed in girls. [Lifetime alcohol drinking (girls): paternal smoking AOR $=1.30,95 \% \mathrm{Cl}=1.29-$ 1.31 ; maternal smoking $\mathrm{AOR}=1.58,95 \% \mathrm{Cl}=1.50-1.66$; parental smoking $\mathrm{AOR}=2.42,95 \% \mathrm{Cl}=2.35-$ 2.49. Current alcohol drinking (girls): paternal smoking $\mathrm{AOR}=1.26,95 \% \mathrm{Cl}=1.25-1.28$; maternal smoking $A O R=1.99,95 \% \mathrm{Cl}=1.87-2.12$; parental alcohol drinking $\mathrm{AOR}=2.63,95 \% \mathrm{Cl}=2.54-2.72]$.

Boys and girls showed different patterns on days and amount of alcohol drinking regarding the parental smoking status. With regard of days, maternal smoking was associated with a higher odds ratio than paternal smoking and parental smoking had higher risks than maternal/paternal smoking in both boys and girls. This tendency became more pronounced as the days of drinking increased (table 2). However, the effects of maternal smoking differed significantly according to sex with respect to drinking volume. In boys, maternal smoking was related to small risk or not related to drinking volume until light to moderate drinking, but the association was increased in binge drinking. In girls, maternal smoking was associated with a higher risk than paternal smoking and parental smoking had higher risks than maternal/paternal smoking consistently [maternal smoking on drinking volume in boys: light $\mathrm{AOR}=.99,95 \% \mathrm{Cl}=.92-1.06$; moderate $\mathrm{AOR}=.80,95 \% \mathrm{Cl}=.71-.90$; binge $\mathrm{AOR}=1.94,95 \% \mathrm{Cl}=1.85-2.03$. In girls: light $\mathrm{AOR}=1.65$, $95 \% \mathrm{Cl}=1.55-1.75 ;$ moderate $\mathrm{AOR}=2.53,95 \% \mathrm{Cl}=2.32-2.75$; binge $\mathrm{AOR}=4.80,95 \% \mathrm{Cl}=4.29-5.01]$.

Table 2 also presents the risk of smoking. In girls, parental smoking was associated with an increased risk compared to paternal/maternal smoking with regarding both lifetime smoking experience and current smoking days and intensity, but this trend was not remarkable among boys. Also, Boys and girls showed different patterns on days and intensity of smoking regarding the parental smoking status. Regarding the number of smoking days, maternal smoking in boys was associated with a higher risk than parental smoking, but girls showed opposite patterns generally. However, this pattern changes when it comes to frequent smoking: Parental smoking was associated with almost 10 times greater risk of smoking more than 20 days per month than parental nonsmoking condition in girls[20 or more days(girls): paternal smoking $A O R=1.20,95 \% \mathrm{Cl}=1.17-1.24$; maternal smoking $\mathrm{AOR}=6.13,95 \% \mathrm{Cl}=5.88-6.79$; parental smoking AOR $=9.41,95 \% \mathrm{Cl}=8.99-9.85]$. With regarding smoking intensity, maternal smoking in boys and parental smoking in girls increased the odd ratio when intensity was low(less than $1 ; 1-9)$. However, as the intensity of smoking increased(10-19; 20 or more), this pattern was reversed(table 2$)$.

Regarding lifetime drug use, maternal smoking in boys and parental smoking in girls were associated with high risk, respectively.

Table 3 presents the results obtained after additional adjustment for second-hand smoke exposure at home. The overall odds ratio reduced, suggesting that second-hand smoke exposure at home have 
mediation effect on adolescents' substance use.-The pattern of the results was similar to that table 2, indicating that parental smoking is associated with a greater risk than parental non-smoking, particularly among girls [Lifetime alcohol drinking (girls): paternal smoking $\mathrm{OR}=1.12,95 \% \mathrm{Cl}=1.11-1.13$; maternal smoking $\mathrm{OR}=1.27,95 \% \mathrm{Cl}=1.20-1.34$; parental smoking $\mathrm{OR}=1.85,95 \% \mathrm{Cl}=1.79-1.90$. Current alcohol drinking (girls): paternal smoking $\mathrm{OR}=1.01,95 \% \mathrm{Cl}=1.00-1.02$; maternal smoking $\mathrm{OR}=1.43,95 \% \mathrm{Cl}=$ 1.34-1.52; parental smoking $\mathrm{OR}=1.77,95 \% \mathrm{Cl}=1.71-1.83$ ]. Regarding alcohol drinking severity (i.e. days and amount), The overall pattern was similar as before adjusted second-hand smoke exposure (table 2 and 3 ).

Similar results were found for smoking risk after adjusting for second-hand smoke exposure at home, with the risk of lifetime smoking experience and current smoking among girls whose both parents smoked being the highest [Lifetime smoking experience (girls whose both parents smoked) $O R=2.76$, $95 \% \mathrm{Cl}=2.66-2.87$. Current smoking (girls whose both parents smoked) $\mathrm{OR}=2.49,95 \% \mathrm{Cl}=2.35-2.63$ ]. Regarding smoking intensity, following adjustment for second-hand smoke exposure at home, odds ratio reduced but the patterns remained similar to those presented in Table 2 (table 3 ). Maternal smoking was found to constitute associated with greater incidence of the lifetime use of drugs or inhalant in boys (OR $=1.45,95 \% \mathrm{Cl}=1.20-1.75)$.

\section{Discussion}

In the present study, we analyzed data from $12^{\text {th }}$ KYRBS to examine the influence of the parental smoking status on the risk of tobacco and alcohol use by adolescents. The effects of parental smoking or maternal/paternal smoking as well as of maternal smoking and paternal smoking were analyzed separately. Different association by sex in the risk of substance use as a result of parental smoking were also explored. Additionally, the unique effect of parental smoking on substance use by adolescents was explored by analyzing the current use, as well as amount and frequency of substance use.

The results showed that smoking by both parents constitutes a significant risk factor for substance use by adolescents compared with smoking by one parent or no smoking by both parents. First, the smoking behavior of both parents increased the smoking rate and degree among adolescents. Evidence clearly shows that parental smoking is a risk factor for smoking by adolescents. Loureiro et al. reported that parental smoking increased the smoking rate among both boys and girls [12], whereas Powell and Chaloupka found that the smoking rate of adolescents increased significantly even when only one parent smoked [13]. Importantly, the results from the present study showed that parental smoking increased smoking risk in children more than maternal/paternal smoking. This suggests that smoking by adolescents is affected not only by the parental smoking status but also by the number of smokers at home.

The identified risk remained significant even when the analysis was adjusted for the effect of secondhand smoke exposure at home. As reported in previous studies, parental attitudes and educational policies toward smoking have a marked impact on adolescent smoking, indicating that parental smoking 
serves as a role model for adolescent smoking $[3,14]$. Okuda et al. showed that adolescents whose both parents smoke show a stronger tendency to smoke and a greater difficulty to quit than those whose only one or no parent smokes [15]. Therefore, parental smoking is more dangerous than maternal/paternal smoking because it increases second-hand exposure to smoking at home, thus allowing children to develop a positive attitude toward smoking.

In the present study, we found that parental smoking affected children of both sexes differently and that the sex of the smoking parent constitutes a different risk factor for the smoking behavior of children. Parental smoking constitutes a significant risk factor for the smoking rate among girls and for the degree of smoking among boys. Maternal smoking produced unique results compared with parental smoking or paternal smoking because it affected the smoking rate of boys and girls differently, significantly increasing the rate of current smoking among boys but decreasing it among girls. Interestingly, girls whose mothers smoked had a higher smoking degree than others.

Previous studies have referred to the differential effects of parental smoking according to the sex of the smoking parent and children. In fact, several studies have found that the effects of both parental and peer smoking on adolescents vary with their sex $[12,13,16]$ and that the effects of parental smoking vary with the sex of the smoking parent $[11,17]$. According to Loureiro et al., parents of the same sex as their children act as a stronger role model for smoking [11], with smoking fathers increasing the smoking rate among boys and smoking mothers increasing this rate among girls. On the other hand, Resen pointed out that irrespective of the sex of children, maternal smoking constitutes a greater risk factor than paternal smoking [17]. Therefore, the available evidence is not fully consistent, suggesting that the effects of parental smoking on the onset and duration of smoking by adolescents are a result of a complex interplay between the sex of parents and that of children [18, 19]. In addition, previous studies conducted in Korea have shown that the school environment and mental health issues such as depression have a significant impact on smoking by adolescents [20-22]. Therefore, further longitudinal studies are needed to closely observe such causal relationships.

Regarding the use of alcohol, the results showed that parental smoking increased the rate and degree of alcohol drinking by adolescents compared with parental nonsmoking or maternal/paternal smoking even after the adjustment for second-hand smoke exposure at home. Currently, there are only few evidences regarding the relationship between parental smoking and alcohol drinking by adolescents, although it is well known that smoking and alcohol drinking are closely related [23]. Some studies have found evidence on a relationship between parental substance use other than alcohol drinking, such as tobacco use, and alcohol drinking by children [24, 25]. Based on large-scale surveys on Korean adolescents, the present study provides convincing evidence that parental smoking can promote alcohol drinking by adolescents and that parental smoking constitutes a higher risk for smoking by adolescents than maternal/paternal smoking.

We also examined the effects exerted by maternal smoking on substance use other than nicotine use by adolescents. We found that while maternal smoking constitutes a risk factor for alcohol drinking behavior 
in children, paternal smoking exerts a relatively smaller effect. These results are consistent with those of a study by Capaldi et al., who found that among the parental use of various substances, the most robust predictor of alcohol drinking by adolescents is maternal smoking [23]. We also revealed that maternal smoking markedly increased the use of illegal substances by boys. Previous studies have reported that a favorable attitude of parents toward the use of various substances, including nicotine, constitutes a risk factor for the use of illegal substances by adolescents [26]. Smoking and alcohol drinking or other substance use by mothers can greatly increase the risk of use of illegal drugs, including marijuana, by adolescents $[27,28]$.

Several potential causes may underlie the negative effects exerted by maternal smoking on substance use by children. First, mothers may have a greater contribution to the attitude of children toward substance use than fathers. Usually, mothers spend more time with their children and tend to develop a more intimate relationship with them than fathers $[29,30]$. Consequently, maternal attitudes may have a greater impact on a child's attitude and value formation [31]. Accordingly, it is assumed that maternal smoking is more likely to lead children to form a permissive attitude toward substance use than paternal smoking.

Second, maternal smoking may lead children to develop antisocial attitudes. Substance use by adolescents is closely related to antisociality [32]. In Asia, including in Korea, smoking by females is considered contrary to social customs because it is considered a masculine trait [33,34]. Therefore, smoking mothers may serve as antisocial role models within Asian cultures, potentially leading to more antisocial behavior (including due to substance use) by adolescents.

The present study has several limitations. First, it was conducted through an online questionnaire, thus reflecting self-reported smoking behavior only. Because the smoking behavior of adolescents can be masked by various reasons, the reliability of self-reported smoking is relatively limited. Therefore, further studies using an objective evaluation of smoking, such as physiological indicators, are required. Second, there may have been confounding variables that were not accounted for. In the present study, the general characteristics of adolescent smokers whose parents were also smokers were easy to explore based on the data. However, other psychosocial factors affecting parent-child relationships, such as adolescents' perceived parental attitudes toward substance use and parenting characteristics, were difficult to assess. We suggest the construction of a sophisticated model aiming at a more accurate evaluation of these characteristics in subsequent studies. Finally, the present study was based on cross-sectional data; therefore, it was difficult to perform a longitudinal observation due to the nature of data. Future studies may provide a causal understanding of the parent-child interaction or sex differences of parent and children on adolescents' smoking behavior through longitudinal observations.

\section{Conclusion}

We used large-scale survey data and confirmed that parental smoking has a significant impact on substance use by adolescents. We found that smoking by both parents constitutes a greater risk factor 
for substance use by adolescents than smoking by only one parent. Moreover, maternal smoking comprises a greater risk than paternal smoking as explored by the analysis of substance use status according to the sex of parents and children after adjusting for second-hand smoke exposure at home, which may have a significant effect on the initiation and maintenance of smoking habit. This suggests that not only the presence of smokers at home but also their number and sex are critical for substance use by adolescents. The accurate evaluation of the family smoking environment and whole-family interventions are necessary to prevent and intervene early against substance use by adolescents.

\section{Abbreviations}

KYRBS (Korea Youth Risk Behavior Web-based Survey)

\section{Declarations}

\section{Ethics approval and consent to participate}

The participants were provided written informed consent to participate in the survey and provided with identification numbers. The KYRBWS was approved by the Institutional Review Board of the Korea Centers for Disease Control and Prevention. (Statistics Korea, approval No. 11758). All methods in the study were carried out with relevant guidelines and regulations.

\section{Consent for publication}

Not applicable"

\section{Availability of data and material}

The datasets used and analyzed during the current study are available from the corresponding author on reasonable request.

\section{Competing interests}

The authors declare that they have no competing interests.

\section{Funding}

The authors did not receive any funding for this paper.

\section{Authors' contributions}

Study conception and design: JL, YK. Statistical expertise, analysis and interpretation of data: JL, YK. Manuscript preparation, supervision, and critical revision of the paper: SM, MHK, KHC, SC, JSA. All authors read and approved the final manuscript. 
Acknowledgements

We gratefully acknowledged the participation of the individuals involved in the study as well as the valuable and helpful comments of the editors and reviewers on this paper.

\section{References}

1. Das JK, Salam RA, Arshad A, Finkelstein Y, Bhutta ZA. Interventions for adolescent substance abuse: An overview of systematic reviews. J Adolesc Health. 2016;59:S61-S75.

2. Robertson EB, David SL, Rao SA. Preventing drug use among children and adolescents: A researchbased guide for parents, educators, and community leaders, 2nd edn. Bethesda, MD: US Department of Health and Human Services; 2003.

3. Dick B, Ferguson BJ. Health for the world's adolescents: A second chance in the second decade. J Adolesc Health. 2015;56:3-6.

4. Cho KS. Prevalence of hardcore smoking and its associated factors in Korea. Health Soc Welf Rev. 2013;33:603-28.

5. Liu JY, Zhao SM, Chen X, Falk E. The influence of peer behavior as a function of social and cultural closeness: A meta-analysis of normative influence on adolescent smoking initiation and continuation. Psychol Bull. 2017;143:1082-115.

6. Myoung Jin Joung, Mi Ah Han, Jong Park, So Yeon Ryu. Association between Family and Friend SmokingStatus and Adolescent Smoking Behavior and E-Cigarette Use in Korea. International journal of environmental research and public health. 2016 Dec;13(12):1183.

7. Ewing SW, Sakhardande A, Blakemore SJ. The effect of alcohol consumption on the adolescent brain: A systematic review of MRI and fMRI studies of alcohol-using youth. Neuroimage Clin. 2014;5:420-37.

8. Simons-Morton B, Haynie DL, Crump AD, Eitel P, Saylor KE. Peer and parent influences on smoking and drinking among early adolescents. Health Education \& Behavior. 2001 Feb;28(1):95-107.

9. Cambron C, Kosterman R, Catalano RF, Guttmannova K, Hawkins JD. Neighborhood, family, and peer factors associated with early adolescent smoking and alcohol use. J Youth Adolesc. 2018;47:369-82.

10. McGovern R, Gilvarry E, Addison M, Alderson H, Geijer-Simpson E, Lingam R, Smart D, Kaner E. The association between adverse child health, psychological, educational and social outcomes, and nondependent parental substance: A rapid evidence assessment. Trauma Violence Abuse. 2018. https:doi.org/10.1177/1524838018772850.

11. Ministry of Health and Welfare of Korea CfDCaP, Ministry of Education: 12th Korea Youth Risk Behavior Web-based Survey. In. Edited by Ministry of Health and Welfare of Korea CfDCaP, Ministry of Education. Sejong City, Korea: MoHW; 2016.

12. Loureiro ML, Sanz-de-Galdeano A, Vuri D. Smoking habits: Like father, like son, like mother, like daughter? Oxf Bull Econ Stat. 2010;72:717-43. 
13. Powell LM, Chaloupka FJ. Parents, public policy and youth smoking. J Policy Anal Manage. 2005;24:93-112.

14. Wilkinson AV, Shete S, Prokhorov AV. The moderating role of parental smoking on their children's attitudes toward smoking among a predominantly minority sample: A cross-sectional analysis. Subst Abuse Treat Prev Policy. 2008;3:18.

15. Okuda K, Okada H, Tanioka T, Osaka K. Family environment factors to impact on the effect of the smoking prevention educational program for elementary and junior high school students. Health. 2018;10:75-89.

16. Chassin L, Presson CC, Sherman SJ, Montello D, McGrew J. Changes in peer and parent influence during adolescence: Longitudinal versus cross-sectional perspectives on smoking initiation. Dev Psychol. 1986;22:327-34.

17. Resen HM. Impact of parents and peers smoking on tobacco consumption behavior of university students. Asian Pac J Cancer Prev. 2018;19:677-81.

18. Kandel DB, Wu P. The contributions of mothers and fathers to the intergenerational transmission of cigarette smoking in adolescence. J Res Adolesc. 1995;5:225-52.

19. White HR, Johnson V, Buyske S. Parental modeling and parenting behavior effects on offspring alcohol and cigarette use: A growth curve analysis. J Subst Abuse. 2000;12:287-310.

20. Heo J, Oh J, Subramanian SV, Kawachi I. Household and school-level influences on smoking behavior among Korean adolescents: A multilevel analysis. PLoS One. 2014;9:e98683.

21. Hong JS, Lee NY, Grogan-Kaylor A, Huang H. Alcohol and tobacco use among South Korean adolescents: An ecological review of the literature. Child Youth Serv Rev. 2011;33:1120-6.

22. Joung MJ, Han MA, Park J, Ryu SY. Association between family and friend smoking status and adolescent smoking behavior and e-cigarette use in Korea. Int J Environ Res Public Health. 2016;13.

23. Capaldi DM, Tiberio SS, Kerr DCR, Pears KC. The relationships of parental alcohol versus tobacco and marijuana use with early adolescent onset of alcohol use. J Stud Alcohol Drugs. 2016;77:95103.

24. Pritchard C, Cox M. Comparison of problematic behaviours of 10th and 11th year Southern English adolescents in 1985 and 2005. Part 1: Trends in gender behaviour. Int J Adolesc Med Health. 2007;19:127-40.

25. Li CY, Pentz MA, Chou CP. Parental substance use as a modifier of adolescent substance use risk. Addiction. 2002;97:1537-50.

26. Schepis TS, Desai RA, Cavallo DA, Smith AE, McFetridge A, Liss TB, Potenza MN, Krishnan-Sarin S. Gender differences in adolescent marijuana use and associated psychosocial characteristics. J Addict Med. 2011;5:65-73.

27. Buu A, DiPiazza C, Wang J, Puttler LI, Fitzgerald HE, Zucker RA. Parent, family, and neighborhood effects on the development of child substance use and other psychopathology from preschool to the start of adulthood. J Stud Alcohol Drugs. 2009;70:489-98. 
28. Kirisci L, Tarter R, Mezzich A, Vanyukov M. Developmental trajectory classes in substance use disorder etiology. Psychol Addict Behav. 2007;21:287-96.

29. Doyle AB, Lawford H, Markiewicz D. Attachment style with mother, father, best friend, and romantic partner during adolescence. J Res Adolesc. 2009;19:690-714.

30. Field T, Lang C, Yando R, Bendell D. Adolescents' intimacy with parents and friends. Adolescence. 1995;30:133-40.

31. Acock AC, Bengtson VL. On the relative influence of mothers and fathers: A covariance analysis of political and religious socialization. J Marriage Fam. 1978;40:519-30.

32. Weiss B, Nguyen T, Trung L, Ngo V, Lau A. Tobacco smoking and antisocial deviance among Vietnamese, Vietnamese-American, and European-American adolescents. J Abnorm Child Psychol. 2019;47:59-69.

33. Jung-Choi $\mathrm{KH}$, Khang $\mathrm{YH}$, Cho HJ. Hidden female smokers in Asia: A comparison of self-reported with cotinine-verified smoking prevalence rates in representative national data from an Asian population. Tob Control. 2012;21:536-42.

34. Park MB, Kim CB, Nam EW, Hong KS. Does South Korea have hidden female smokers: Discrepancies in smoking rates between self-reports and urinary cotinine level. BMC Womens Health. 2014;14:156.

\section{Tables}

Table 1 Demographic variables 


\begin{tabular}{|c|c|c|c|c|c|}
\hline Characteristics & $\begin{array}{l}\text { Parental } \\
\text { nonsmoking } \\
(\mathrm{n}=1,481,156)\end{array}$ & $\begin{array}{l}\text { Paternal } \\
\text { smoking } \\
(\mathrm{n}=108,934)\end{array}$ & $\begin{array}{l}\text { Maternal } \\
\text { smoking } \\
(\mathrm{n}=13,738)\end{array}$ & $\begin{array}{l}\text { Parental } \\
\text { smoking } \\
(\mathrm{n}=42,566)\end{array}$ & $\begin{array}{l}p- \\
\text { value }\end{array}$ \\
\hline Female sex $(n, \%)$ & 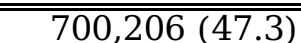 & 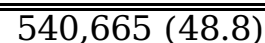 & 6,498(47.3) & "21,677 (50.9) & "<.001† \\
\hline Age [years; M (SD)] & $15.08(1.74)$ & $15.02(1.73)$ & $15.44(1.71)$ & $15.21(1.70)$ & $<.001 \dagger$ \\
\hline Educated [M (SD)] & $9.62(1.69)$ & $9.57(1.69)$ & $9.95(1.63)$ & $9.76(1.68)$ & $<.001 \dagger$ \\
\hline Urbanity (n, \%) & & & & & $<.001 \dagger$ \\
\hline Metropolitan cites & $654,014(44.2)$ & $476,170(42.9)$ & $5,441(39.6)$ & $16,421(38.6)$ & \\
\hline Small and medium cites & $753,636(50.9)$ & $567,587(51.2)$ & $7,259(52.8)$ & $22,875(53.7)$ & \\
\hline Rural areas & $73,505(5.0)$ & $65,176(5.9)$ & $1,037(7.5)$ & $3,271(7.7)$ & \\
\hline Paternal educational level (n, \%) & & & & & $<.001 \dagger$ \\
\hline College and higher & $888,226(60.0)$ & $548,377(49.5)$ & 4,196 (30.5) & $13,080(30.7)$ & \\
\hline High school & $364,371(24.6)$ & $345,515(31.2)$ & $5,231(38.1)$ & $17,987(42.3)$ & \\
\hline Middle school and below & $26,492(1.8)$ & $20,842(1.9)$ & $638(4.6)$ & $2,828(6.6)$ & \\
\hline Unknown & $202,067(13.6)$ & $194,199(17.5)$ & $3,671(26.7)$ & $8,671(20.4)$ & \\
\hline Maternal educational level (n, \%) & & & & & $<.001 \dagger$ \\
\hline College and higher & $782,489(52.8)$ & $489,715(44.2)$ & $2,978(21.7)$ & $10,509(24.7)$ & \\
\hline High school & $474,065(32.0)$ & $418,471(37.7)$ & $6,594(48.0)$ & $21,631(50.8)$ & \\
\hline Middle school and below & $22,626(1.5)$ & $17,695(1.6)$ & $812(5.9)$ & $2,108(5.0)$ & \\
\hline Unknown & $201,976(13.6)$ & $183,052(16.5)$ & $3,354(24.4)$ & $8,319(19.5)$ & \\
\hline Academic achievement & & & & & $<.001 \dagger$ \\
\hline High & $224,616(15.2)$ & $129,720(11.7)$ & $922(6.7)$ & $3,711(8.7)$ & \\
\hline Middle high & $404,759(27.3)$ & $274,423(24.7)$ & $2,621(19.1)$ & $8,477(19.9)$ & \\
\hline Average & $433,247(29.3)$ & $326,435(29.4)$ & $4,461(32.5)$ & $10,441(24.5)$ & \\
\hline Middle low & $305,463(20.6)$ & $266,761(24.1)$ & $3,511(25.6)$ & $11,959(28.1)$ & \\
\hline Low & $113,070(7.6)$ & $111,595(10.1)$ & $2,223(16.2)$ & 7,978 (18.7) & \\
\hline Family economic status & & & & & $<.001 \dagger$ \\
\hline High & $171,223(11.6)$ & $94,622(8.5)$ & $1,183(8.6)$ & $2,229(5.2)$ & \\
\hline Middle high & $473,344(32.0)$ & 309,285 (27.9) & $3,041(22.1)$ & 7,929 (18.6) & \\
\hline Average & $687,342(46.4)$ & $558,474(50.4)$ & $6,646(48.4)$ & $20,449(48.0)$ & \\
\hline Middle low & $128,256(8.7)$ & $125,955(11.4)$ & $2,366(17.2)$ & $9,257(21.7)$ & \\
\hline Low & $20,991(1.4)$ & $20,598(1.9)$ & $501(3.6)$ & $2,704(6.4)$ & \\
\hline $\begin{array}{l}\text { Second-hand smoking at home } \\
\text { [days; M, (SD)] }\end{array}$ & $.26(.99)$ & $1.69(2.29)$ & $2.18(2.69)$ & $3.17(2.83)$ & $<.001 \dagger$ \\
\hline
\end{tabular}

Table 2 Substance use by adolescents 


\begin{tabular}{|c|c|c|c|c|c|c|}
\hline \multirow[t]{2}{*}{ Variable } & \multicolumn{2}{|c|}{ Total } & \multicolumn{2}{|l|}{ Boys } & \multicolumn{2}{|l|}{ Girls } \\
\hline & $\begin{array}{c}\text { OR }(95 \% \mathrm{CI}) \\
\beta R(9)\end{array}$ & $p$-value & $\begin{array}{c}\text { OR }(95 \% \mathrm{CI}) \\
\beta(t)\end{array}$ & $p$-value & $\begin{array}{c}\text { OR }(95 \% \mathrm{CI}) \\
\beta R(9)\end{array}$ & $p$-value \\
\hline
\end{tabular}

\section{Lifetime alcohol}

drinking

\begin{tabular}{lcccccc}
\cline { 5 - 7 } Parental nonsmoking & 1.00 & & 1.00 & & 1.00 & \\
Paternal smoking & $1.24(1.23-1.25)$ & $<.001$ & $1.22(1.21-1.22)$ & $<.001$ & $1.30(1.29-1.31)$ & $<.001$ \\
Maternal smoking & $1.44(1.39-1.49)$ & $<.001$ & $1.35(1.28-1.42)$ & $<.001$ & $1.58(1.50-1.66)$ & $<.001$ \\
Parental smoking & $1.87(1.83-1.91)$ & $<.001$ & $1.51(1.46-1.55)$ & $<.001$ & $2.42(2.35-2.49)$ & $<.001$
\end{tabular}

Current alcohol drinking

Parental nonsmoking

Paternal smoking

Maternal smoking

Parental smoking

Drinking days

Paternal smoking

Maternal smoking

Parental smoking

Drinking volume

Paternal smoking

Maternal smoking

Parental smoking

Lifetime smoking experience

Parental nonsmoking

Paternal smoking

Maternal smoking

Parental smoking

Current smoking

Parental nonsmoking

Paternal smoking

Maternal smoking

Parental smoking

Smoking days

\begin{tabular}{ccccccc}
\hline Paternal smoking & $.04(14.91)$ & $<.001$ & $.04(14.73)$ & $<.001$ & $.04(6.01)$ & $<.001$ \\
\hline Maternal smoking & $-.01(-3.13)$ & .002 & $-.02(-7.99)$ & $<.001$ & $.07(11.59)$ & $<.001$ \\
\hline Parental smoking & $.04(16.17)$ & $<.001$ & $.06(21.10)$ & $<.001$ & $.06(8.48)$ & $<.001$ \\
\hline Smoking volume & & & & & & \\
\hline Paternal smoking & $-.01(-1.70)$ & .088 & $.00(.26)$ & .795 & $-.03(-4.49)$ & $<.001$ \\
\hline Maternal smoking & $-.02(-5.86)$ & $<.001$ & $-.03(-9.70)$ & $<.001$ & $.05(8.28)$ & $<.001$ \\
\hline Parental smoking & $.02(8.67)$ & $<.001$ & $.04(14.78)$ & $<.001$ & $.00(.23)$ & .816 \\
\hline Lifetime drug use & & & & & 1.00 & \\
\hline Parental nonsmoking & 1.00 & & 1.00 & & $.76(.71-.80)$ & $<.001$ \\
\hline Paternal smoking & $.80(.77-.83)$ & $<.001$ & $.83(.80-.87)$ & $<.001$ & $.76-001$ \\
\hline Maternal smoking & $1.53(1.29-1.81)$ & $<.001$ & $2.38(1.98-2.87)$ & $<.001$ & $.41(.25-.66)$ & $<.001$ \\
\hline Parental smoking & $1.58(1.43-1.74)$ & $<.001$ & $.79(.65-.95)$ & .012 & $2.45(2.17-2.77)$ & $<.001$ \\
\hline
\end{tabular}

Smoking volume

\begin{tabular}{ccccccc}
\hline Paternal smoking & $.04(14.91)$ & $<.001$ & $.04(14.73)$ & $<.001$ & $.04(6.01)$ & $<.001$ \\
\hline Maternal smoking & $-.01(-3.13)$ & .002 & $-.02(-7.99)$ & $<.001$ & $.07(11.59)$ & $<.001$ \\
\hline Parental smoking & $.04(16.17)$ & $<.001$ & $.06(21.10)$ & $<.001$ & $.06(8.48)$ & $<.001$ \\
\hline Smoking volume & & & & & & \\
\hline Paternal smoking & $-.01(-1.70)$ & .088 & $.00(.26)$ & .795 & $-.03(-4.49)$ & $<.001$ \\
\hline Maternal smoking & $-.02(-5.86)$ & $<.001$ & $-.03(-9.70)$ & $<.001$ & $.05(8.28)$ & $<.001$ \\
\hline Parental smoking & $.02(8.67)$ & $<.001$ & $.04(14.78)$ & $<.001$ & $.00(.23)$ & .816 \\
\hline Lifetime drug use & & & & & 1.00 & \\
\hline Parental nonsmoking & 1.00 & & 1.00 & & $.76(.71-.80)$ & $<.001$ \\
\hline Paternal smoking & $.80(.77-.83)$ & $<.001$ & $.83(.80-.87)$ & $<.001$ & $.76-001$ \\
\hline Maternal smoking & $1.53(1.29-1.81)$ & $<.001$ & $2.38(1.98-2.87)$ & $<.001$ & $.41(.25-.66)$ & $<.001$ \\
\hline Parental smoking & $1.58(1.43-1.74)$ & $<.001$ & $.79(.65-.95)$ & .012 & $2.45(2.17-2.77)$ & $<.001$ \\
\hline
\end{tabular}

Lifetime drug use

\begin{tabular}{ccccccc}
\hline Paternal smoking & $.04(14.91)$ & $<.001$ & $.04(14.73)$ & $<.001$ & $.04(6.01)$ & $<.001$ \\
\hline Maternal smoking & $-.01(-3.13)$ & .002 & $-.02(-7.99)$ & $<.001$ & $.07(11.59)$ & $<.001$ \\
\hline Parental smoking & $.04(16.17)$ & $<.001$ & $.06(21.10)$ & $<.001$ & $.06(8.48)$ & $<.001$ \\
\hline Smoking volume & & & & & & \\
\hline Paternal smoking & $-.01(-1.70)$ & .088 & $.00(.26)$ & .795 & $-.03(-4.49)$ & $<.001$ \\
\hline Maternal smoking & $-.02(-5.86)$ & $<.001$ & $-.03(-9.70)$ & $<.001$ & $.05(8.28)$ & $<.001$ \\
\hline Parental smoking & $.02(8.67)$ & $<.001$ & $.04(14.78)$ & $<.001$ & $.00(.23)$ & .816 \\
\hline Lifetime drug use & & & & & 1.00 & \\
\hline Parental nonsmoking & 1.00 & & 1.00 & & $.76(.71-.80)$ & $<.001$ \\
\hline Paternal smoking & $.80(.77-.83)$ & $<.001$ & $.83(.80-.87)$ & $<.001$ & $.76-001$ \\
\hline Maternal smoking & $1.53(1.29-1.81)$ & $<.001$ & $2.38(1.98-2.87)$ & $<.001$ & $.41(.25-.66)$ & $<.001$ \\
\hline Parental smoking & $1.58(1.43-1.74)$ & $<.001$ & $.79(.65-.95)$ & .012 & $2.45(2.17-2.77)$ & $<.001$ \\
\hline
\end{tabular}

$\begin{array}{cc}1.00 & \\ 1.22(1.21-1.23) & <.001 \\ 1.37(1.31-1.43) & <.001 \\ 2.01(1.96-2.05) & <.001\end{array}$

1.00

$1.21(1.20-1.22)<.001$

$1.01(.94-1.07) \quad .890$

$1.59(1.53-1.64)<.001$
$.02(8.06)$

$.02(11.20)$

.001 (2.98)
$<.001$

$<.001$

.003
1.00

$1.26(1.25-1.28)<.001$

$1.99(1.87-2.12)<.001$

$2.63(2.54-2.72)<.001$

$\begin{array}{ll}.02(10.31) & <.001 \\ .02(14.20) & <.001\end{array}$

$\begin{array}{ll}.02(14.52) & <.001 \\ .02(13.14) & <.001 \\ .05(28.91) & <.001\end{array}$

$.02(8.90)$

$.02(11.09)$

$<.001$

$<.001$

$.02(7.76)$

$<.001$

$.03(14.36)<.001$

.06 (22.65)

$<.001$
1.00

1.17 (1.16-1.18)

$1.21(1.15-1.26)$

$2.08(2.03-2.13)$
1.00

$<.001$

$<.001$

$<.001$
$1.22(1.21-1.23)<.001$

$1.14(1.08-1.21)<.001$

$1.56(1.51-1.61)<.001$
$.05(18.54)$

$.03(10.21)$

$<.001$

.09 (34.74)

1.00

$1.21(1.19-1.22)<.001$

$1.60(1.47-1.74)<.001$

$4.00(3.86-4.15)<.001$

\subsection{0}

$1.18(1.11-1.13)$

$1.30(1.22-1.39)$

$2.21(2.14-2.28)$

\subsection{0}

$<.001$

$1.17(1.16-1$

$<.001$

$<.001$
$1.58(1.47-1.70)<.001$

$1.62(1.55-1.69)<.001$

\subsection{0}

$.76(.64-.90) \quad .002$

$4.72(4.49-4.97)<.001$
$.02(5.57)<.001$

Models adjusted for age, urbanity, academic achievement, paternal educational level, maternal educational level, and socioeconomic status.

Table 3 Substance use by adolescents adjusted for second-hand smoking at home 


\begin{tabular}{|c|c|c|c|c|c|c|}
\hline \multirow[t]{2}{*}{ Variable } & \multicolumn{2}{|c|}{ Total } & \multicolumn{2}{|l|}{ Boys } & \multicolumn{2}{|l|}{ Girls } \\
\hline & $\begin{array}{c}\text { OR }(95 \% \mathrm{CI}) \\
\beta R(9)\end{array}$ & $p$-value & $\begin{array}{c}\text { OR }(95 \% \text { CI }) \\
\beta R(9)\end{array}$ & $p$-value & $\begin{array}{c}\text { OR (95\% CI) } \\
\beta R(9)\end{array}$ & $p$-value \\
\hline
\end{tabular}

\section{Lifetime alcohol}

drinking

\begin{tabular}{lcccccc}
\cline { 5 - 7 } Parental nonsmoking & 1.00 & & 1.00 & & 1.00 & \\
Paternal smoking & $1.10(1.09-1.10)$ & $<.001$ & $1.08(1.07-1.09)$ & $<.001$ & $1.12(1.11-1.13)$ & $<.001$ \\
Maternal smoking & $1.23(1.18-1.27)$ & $<.001$ & $1.20(1.14-1.26)$ & $<.001$ & $1.27(1.20-1.34)$ & $<.001$ \\
Parental smoking & $1.47(1.44-1.50)$ & $<.001$ & $1.20(1.16-1.23)$ & $<.001$ & $1.85(1.79-1.90)$ & $<.001$
\end{tabular}

Current alcohol drinking

\begin{tabular}{lcccccc} 
Parental nonsmoking & 1.00 & \multicolumn{3}{c}{1.00} & 1.00 \\
Paternal smoking & $.99(.98-1.00)$ & .004 & $.99(.98-1.00)$ & .050 & $1.01(1.00-1.02)$ & .129 \\
Maternal smoking & $1.04(1.00-1.09)$ & .064 & $.82(.77-.87)$ & $<.001$ & $1.43(1.34-1.52)$ & $<.001$ \\
Parental smoking & $1.35(1.32-1.39)$ & $<.001$ & $1.07(1.03-1.11)$ & $<.001$ & $1.77(1.71-1.83)$ & $<.001$
\end{tabular}

Alcohol drinking days

$\begin{array}{lcccccc}\text { Paternal smoking } & -.02(-13.10) & <.001 & -.02(-7.56) & <.001 & -.03(-8.75) & <.001 \\ \text { Maternal smoking } & .01(6.41) & <.001 & .02(8.46) & <.001 & .01(2.64) & .008 \\ \text { Parental smoking } & .00(-.56) & .575 & -.01(8.46) & <.001 & .03(10.62) & <.001\end{array}$

Alcohol drinking volume

$\begin{array}{lcccccc}\text { Paternal smoking } & -.01(-5.88) & <.001 & -.01(-3.87) & <.001 & .00(-.16) & .875 \\ \text { Maternal smoking } & .02(9.63) & <.001 & .02(8.85) & <.001 & .02(7.04) & <.001 \\ \text { Parental smoking } & .03(15.32) & <.001 & .01(6.77) & <.001 & .06(21.34) & <.001\end{array}$

Lifetime smoking experience

Parental nonsmoking

Paternal smoking

1.00

Maternal smoking

Parental smoking

Current smoking

Parental nonsmoking

Paternal smoking

Maternal smoking

Parental smoking

Smoking days

$\begin{array}{lcccccc}\text { Paternal smoking } & .02(7.35) & <.001 & .02(7.37) & <.001 & .02(2.18) & .029 \\ \text { Maternal smoking } & .01(-4.21) & <.001 & -.02(-8.84) & <.001 & .06(10.27) & <.001 \\ \text { Parental smoking } & .03(10.05) & <.001 & .05(17.00) & <.001 & .02(3.12) & .002\end{array}$

Smoking volume

\begin{tabular}{lcccccc} 
Paternal smoking & $-.04(-15.45)$ & $<.001$ & $-.04(-13.05)$ & $<.001$ & $-.06(-9.69)$ & $<.001$ \\
Maternal smoking & $-.02(-7.96)$ & $<.001$ & $-.03(-11.38)$ & $<.001$ & $.04(6.45)$ & $<.001$ \\
\hline Parental smoking & $-.01(-2.55)$ & .011 & $.02(7.33)$ & $<.001$ & $-.05(-6.87)$ & $<.001$
\end{tabular}

Lifetime drug use

Parental nonsmoking
Paternal smoking
Maternal smoking
Parental smoking

1.00

$.42(.40-.44)<.001$

$.66(.56-.79)<.001$

$.53(.48-.58)$
1.00

$1.05(1.04-1.06)<.001$

$.98(.93-1.04)$

.535

$.97(.95-.99)$

$1.15(1.01-1.25)$

$1.16(1.13-1.20)<.001$
$2.76(2.66-2.87)<.001$
1.00

$.93(.92-.95)<.001$

$1.28(1.19-1.37)<.001$

$.74(.71-.76)$

$.42(.35-.49)<.001$

$2.49(2.35-2.63)<.001$ moking

$<.001$
1.00

$.52(.50-.55)<.001$

$1.45(1.20-1.75)<.001$

$.33(.28-.40)$
1.00

$28(.26-.30)<.001$

$.10(.06-.16)<.001$

$.54(.48-.62)<.001$

Models adjusted for age, urbanity, academic achievement, paternal educational level, maternal educational level, socioeconomic status, and second-hand smoking. 